\title{
Nanocrystalline and Polycrystalline Phases Present in the Protective Metalloceramic Coatings
}

\author{
L. Górski ${ }^{a}$ AND A. PaWŁowski ${ }^{b}$ \\ ${ }^{a}$ Institute of Atomic Energy, 05-400 Otwock-Świerk, Poland \\ ${ }^{b}$ Institute of Metallurgy and Material Science, Polish Academy of Sciences \\ Reymonta 25, 30-059 Kraków, Poland
}

\begin{abstract}
New data about the structure of high-temperature resistant metalloceramic plasma sprayed coatings in micro and nano areas are presented. Application of the new instrumental methods: transmission electron microscopy combined with selected area electron diffraction made it possible to obtain these data. The first layer in Ni based metallic bondcoat shows nanocrystalline structure. External ceramic layer based on stabilised $\mathrm{ZrO}_{2}$ is polycrystalline and contains both cubic and tetragonal crystalline phases. Local inhomogeneities in coatings phase composition are determined.
\end{abstract}

PACS numbers: $61.50 . \mathrm{Ks}, 81.30 .-\mathbf{t}$

\section{Introduction}

The presented paper deals with the problem of the high-temperature resistant protective coatings deposited mainly by plasma spraying technology. Coatings of this type are used in numerous technical applications. The most important types of such coatings are the so-called thermal barrier coatings (TBC) used among others in gas turbines and Diesel engines [1-4].

TBC coatings reduce the temperature attained by the metal base components and act as a barrier for hot corrosion. These coatings are the result of advanced technology combining suitable choice of the substrate, metallic bondcoat (mainly superalloys on $\mathrm{Ni}$ base e.g. NiCrAlY) and essential external ceramic layer based on $\mathrm{Al}_{2} \mathrm{O}_{3}$ and $\mathrm{ZrO}_{2}$.

In the earlier works resistance of such coatings to thermal shocks was studied on special experimental arrangement. Observations of the resulted macroscopic 
coatings degradation are accompanied by studies of the surface structure changes with the use of light microscope (LM) and scanning electron microscope (SEM) and also by X-ray diffraction (XRD) studies of phase transitions caused by the plasma spraying and thermal shocks conditions [5-7].

The purposes of the presented paper are of both, research and practical character. The research purpose is to determine local changes in coatings phase composition, especially effects occurring in the areas near to the metal-ceramic and substrate-bondcoat interfaces. It should be useful in the realisation of the practical goal namely to obtain coatings with increasing resistance to high temperature processes. For the above purposes new instrumental research methods: transmission electron microscopy (TEM) combined with electron diffraction in selected areas (SAED) have been applied. Special thinning technique necessary to study coatings by the TEM methods has been worked out in the Institute of Metallurgy and Material Science.

The presented work is the result of cooperation between the Institute of Atomic Energy and the Institute of Metallurgy and Material Science. Report on the first joint research in this field is described below.

\section{Experimental}

The coatings studied in this work consist of two layers:

1. metallic bondcoat - NiCrAlY, Cr - 25 weight $\%, \mathrm{Al}-6 \%, \mathrm{Y}-0.5-1.0 \%$, $\mathrm{Ni}$ - balance, thickness about $100 \mu \mathrm{m}$;

2. ceramic layer, $\mathrm{ZrO}_{2}+8-20$ weight $\% \mathrm{Y}_{2} \mathrm{O}_{3}$, thickness $200-300 \mu \mathrm{m}$.

Coatings are deposited by the method of atmospheric plasma spraying (APS) with the use of PN-120 plasmatrone in Świerk. The process is carried fully automatically with microprocessor controlled mechanical robot. The process parameters and experimental details are described elsewhere $[7,8]$.

XRD patterns for materials in the form of powders before spraying and plasma sprayed coatings have been obtained. Coatings are studied by X-ray methods on the surface and at the various depths.

Microstructure was studied firstly by SEM and next by TEM methods. Ion etching technique is used for thinning the specimens [9]. Microscopic observations by the TEM methods with the use of Philips CM 20 Twin electron microscope are accompanied by the SAED methods. Chemical composition in micro and nano areas is studied by the energy dispersive spectroscopy (EDS) methods.

\section{Results and discussion}

Materials applied for spraying are supplied in the form of powder with average grain size $10-50 \mu \mathrm{m}$. The shapes of individual grains are mainly spherical. 
XRD patterns of NiCrAlY show that only one phase is present: stable solid solution on Ni base (cubic system, fcc crystal lattice). Diffraction patterns of stabilised zirconium oxide show the existence of cubic phase as a main component with slight tetragonal split visible on 200 and 311 peaks. The small amount of monoclinic, unstabilised $\mathrm{ZrO}_{2}$ is also present. Example of such pattern is presented in Fig. 1. The diffraction patterns of coating surface show only slight differences in the comparison with pattern from Fig. 1. Tetragonal split is better visible and the amount of monoclinic phase is decreased.

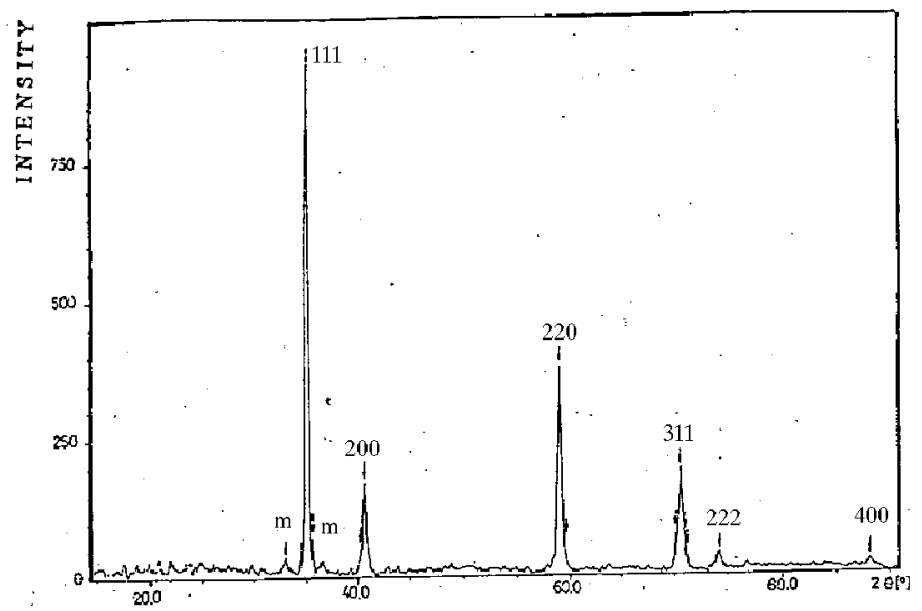

Fig. 1. X-ray diffraction pattern of $\mathrm{ZrO}_{2}+8 \% \mathrm{Y}_{2} \mathrm{O}_{3}$ in the form of powder before spraying, indices listed for cubic phase, $\mathrm{m}-$ monoclinic phase.

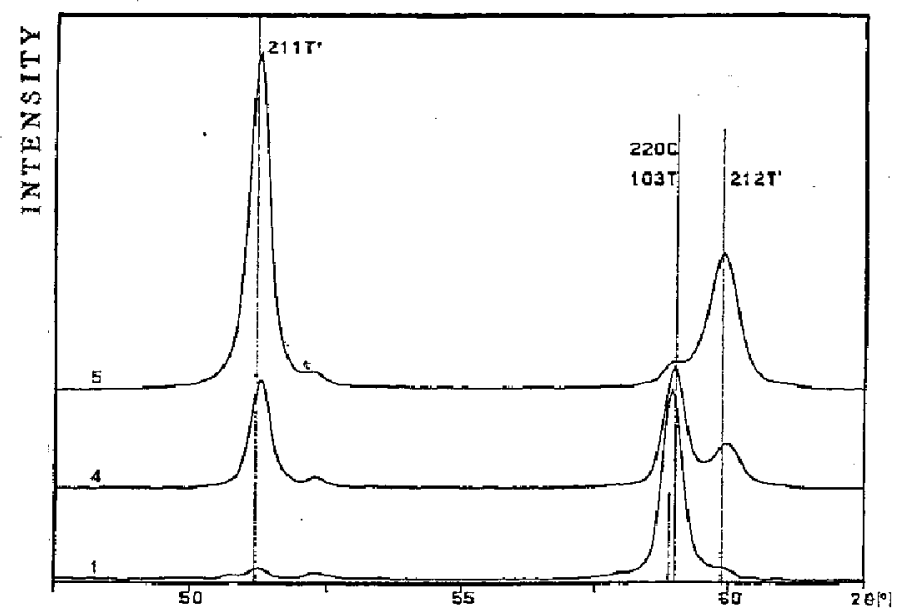

Fig. 2. X-ray diffraction pattern of the coating sprayed from material showed in Fig. 1, 1 - coating surface, $4-125 \mu \mathrm{m}$ depth, $5-150 \mu \mathrm{m}$ depth, $\mathrm{c}-$ cubic, t - tetragonal phases. 
More changes are detected on XRD patterns made at different depths of ceramic layer. The amount of tetragonal phase is increased and the amount of cubic phase is decreased. This effect is demonstrated in the enlarged part of diffraction pattern presented in Fig. 2. It should be emphasized that the content of tetragonal phases especially of the non-transformable tetragonal phase on the coating surface is considerably lower and appears rather at the presence of higher (above 10\%) $\mathrm{Y}_{2} \mathrm{O}_{3}$ content $[7,10]$.

Small deviations of lattice parameters in $\mathrm{ZrO}_{2}$ especially for cubic phase are also observed. These deviations connected with local differences in coatings phase composition may be caused by plasma spraying process conditions. Very short time of flight (ms range) and subsequent rapid cooling (about $10^{6} \mathrm{~K} / \mathrm{s}$ ) of melted powder particles incident on cold substrate (especially for insulated ceramics) form conditions far from thermodynamical equilibrium. Therefore occurrence of different phase transitions and local differences in coatings phase compositions are quite possible and even probable.

First TEM observations of the areas near to phase boundaries give new information which was not known previously. Observations in transmission electron microscope show a few sublayers existing in the areas of metallic and ceramic layers. First sublayer in the metallic bondcoat nearest to substrate is nanocrystalline with amorphic fragments. In the next sublayer crystallite sizes are increased and this layer is fairly polycrystalline. In the ceramic layer one can observe the existence

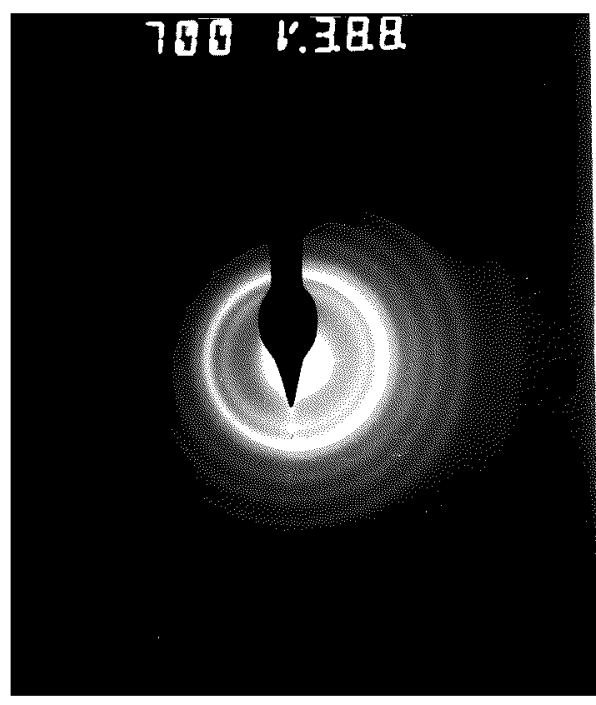

Fig. 3

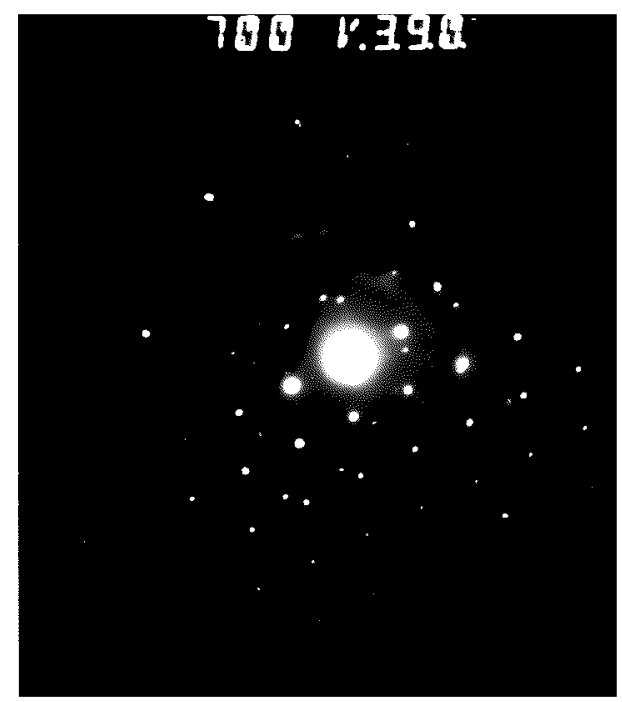

Fig. 4

Fig. 3. Electron diffraction pattern from the nanocrystalline metallic sublayer.

Fig. 4. Electron diffraction pattern from the crystalline ceramic sublayer. 
of polycrystalline structure with two coexisting phases: cubic and tetragonal. Electron diffraction patterns of nanocrystalline metallic sublayer and polycrystalline ceramic layer are presented in Fig. 3 and Fig. 4, respectively.

These effects are caused by the above mentioned high cooling rate during the plasma sprayed coatings formation. First layer in contact to the substrate may solidify as nanocrystalline because there is not enough time to form crystalline phases with long distance ordering. The next layers have a higher degree of crystallinity due to slower process of crystallisation for particles surrounded by neighbouring insulated ceramic particles. Local differences in $\mathrm{Y}_{2} \mathrm{O}_{3}$ amounts in $\mathrm{ZrO}_{2}$ coatings may be the reason for the above mentioned deviations of zirconia lattice constants.

These experiments give new information about the structure of thermally sprayed coatings. Further works devoted to this topic is in progress.

\section{Conclusions}

The specific conditions of plasma spraying process give rise to local inhomogeneities in coatings phase composition. Near to the interface with substrate the bondcoat exists in the nanocrystalline form with amorphic fragments. Further sublayers show the increasing degree of crystallinity and crystallite sizes. External ceramic layer is polycrystalline and contains both cubic and tetragonal phases of $\mathrm{ZrO}_{2}$. These new data were obtained due to the application of new instrumental research methods: TEM combined with SAED.

\section{References}

[1] S. Stecura, Am. Ceram. Soc. Bull. 56, 1082 (1977).

[2] A.H. Nicoll, H. Gruener, Surf. Eng. 1, 11 (1985).

[3] S. Strangman, Thin Solid Films 127, 93 (1985).

[4] R.J. Brandon, R. Taylor, Surf. Coat. Technol. 50, 141 (1992).

[5] L. Górski, T. Wolski, in: Euro-Ceramics II, Vol. II, Eds. G. Ziegler, H. Hausner, DKG, Koln 1993, p. 1739.

[6] L. Górski, in: Ceramic Processing, Science and Technology, Eds. H. Hausner, G.L. Messing, T. Shirano, American Ceramic Society, Columbus, Ohio 1995, p. 93.

[7] L. Górski, Report IAE nr 47/A, 1999.

[8] L. Górski, T. Wolski, D. Gostyński, Report IAE nr 19/A, 1996.

[9] A. Pawłowski, M. Bućko, Z. Pędzich, J. Ion Conductors, 2001, in press.

[10] L. Górski, Inż. Mat., nr 5 (112), 416 (1999). 